- 研究报告・

\title{
珠江河口区大型底栖动物群落结构
}

\author{
周细平 ${ }^{1,2}$ 李 贞 ${ }^{1}$ 吴培芳 ${ }^{1}$ 吴 茜 ${ }^{1}$ 陈逸欣 ${ }^{1}$ \\ 刘康格 ${ }^{1}$ 刘东䎦 $^{3}$ 王玉珏 $^{4}$ 王跃启 $^{4}$ \\ 1 (厦门大学嘉庚学院环境科学与工程学院, 福建漳州 363105) \\ 2 (厦门大学嘉庚学院河口生态安全与环境健康福建省高校重点实验室, 福建漳州 363105) \\ 3 (华东师范大学河口与海岸学国家重点实验室, 上海 200062) \\ 4 (中国科学院海岸带环境过程与生态修复重点实验室, 山东烟台 264003)
}

摘要: 河口区大型底栖动物具有的重要群落特征往往可以反映群落所经历的环境污染。为更好地了解珠江河口区 大型底栖动物群落结构, 作者于2014年11月至2015年8月进行了 4 个季度的大型底栖动物调查, 并利用PRIMER 6.0 软件进行群落生物多样性指数计算、群落等级聚类(Cluster)和非度量多维标度排序(nMDS)分析。研究结果显示: 珠 江河口区共获得大型底栖动物 52种, 优势种包括光滑河篮蛤 (Potamocorbula laevis)、中国绿螂(Glaucomya chinensis)、焦河篮蛤(Potamocorbula ustulata)和羽须鰓沙蚕(Dendroneris pinnaticirrus)。大型底栖动物年平均密度 为 $269.3 \mathrm{ind} . / \mathrm{m}^{2}$, 年平均生物量为 $129.61 \mathrm{~g} / \mathrm{m}^{2}$ 。12个站次的丰富度指数 $(D)$ 、均匀度指数 $\left(J^{\prime}\right)$ 和Shannon-Wiener多样 性指数 $\left(H^{\prime}\right)$ 平均值分别为 $1.81 \pm 1.38 、 0.50 \pm 0.27$ 和 $1.60 \pm 1.13$ 。该结果显示除P 01 断面的秋季和冬季环境质量为优 良外, 其他站位在不同季度都显示出轻度到重度的污染。Cluster聚类分析和nMDS标序结果表明, P01断面与P02和 P03断面群落相似度较低, 与断面地理分布情况一致; P02断面和P03断面存在交叉聚集, 群落相似度较高。结合环 境因子结果可知, 沉积物理化因子与群落分布特征相关性较大, 其中最能解释珠江河口区群落多样性分布特征的 环境因子为盐度和 $\mathrm{pH}$ 值。

关键词：珠江口; 大型底栖动物; 群落结构

\section{The structure of macrobenthic community in Pearl River Estuary}

Xiping Zhou ${ }^{1,2^{*}}$, Zhen $\mathrm{Li}^{1}$, Peifang $\mathrm{Wu}^{1}, \mathrm{Xi} \mathrm{Wu}{ }^{1}$, Yixin $\mathrm{Chen}^{1}$, Kangge $\mathrm{Liu}^{1}$, Dongyan $\mathrm{Liu}^{3}$, Yujue Wang ${ }^{4}$, Yueqi Wang ${ }^{4}$

1 School of Environmental Science and Engineering, Tan Kah Kee College, Xiamen University, Zhangzhou, Fujian 363105

2 Key Laboratory of Estuarine Ecological Security and Environmental Health, Tan Kah Kee College, Xiamen University, Zhangzhou, Fujian 363105

3 State Key Laboratory of Estuarine and Coastal Research, East China Normal University, Shanghai 200062

4 Key Laboratory of Coastal Environmental Processes and Ecological Remediation, Chinese Academy of Sciences, Yantai, Shandong 264003

Abstract: The macrobenthic communities of estuaries are often indicative of important community traits, such as the environmental pollution a community may experience. To better understand the structure of Pearl River Estuary's macrobenthic community, macrobenthic species were identified based on investigations carried out from November 2014 to August 2015, and biodiversity analyses were performed. More specifically, biodiversity index calculations, cluster analysis, and nMDS (non-metric MDS) analysis were performed used PRIMER 6.0 software. While 52 macrobenthic species were identified in the Pearl River estuary, the dominant species in this study area were Potamocorbula laevis, Glaucomya chinensis, Potamocorbula ustulata and Dendroneris pinnaticirrus. The annual mean density of macrobenthos in the Pearl River Estuary was $269.3 \mathrm{ind} . / \mathrm{m}^{2}$ and the annual mean biomass was $129.61 \mathrm{~g} / \mathrm{m}^{2}$. The mean values of richness index $(D)$, evenness index $\left(J^{\prime}\right)$ and Shannon-Wiener diversity index $\left(H^{\prime}\right)$ of 12 samplings were $1.81 \pm 1.38 、 0.50 \pm 0.27$

收稿日期: 2019-09-20; 接受日期: 2019-10-13

基金项目: 国家自然科学基金(41606119)、福建省自然科学基金(2017J05068)和福建省高等学校新世纪优秀人才支持计划(闽教科（2017）52 号)

* 通讯作者 Author for correspondence. E-mail: zoeyzhou@xujc.com 
and $1.60 \pm 1.13$, respectively. The results showed a range of environmental quality from clean to severe pollution, in which only P01 section indicated clean environmental quality in autumn and winter. Cluster and nMDS results revealed that low community similarity were observed among P01 section and P02 together with P03 sections, potentially due to the geographical distribution factors. Additionally, the P02 section and P03 section gathered crosswise with higher community similarity. Our results suggested the combination of environmental factors with physical and chemical sediment factors were significantly correlated with the distribution characteristics of communities. Also to note, water salinity and $\mathrm{pH}$ can help explain the biodiversity distribution pattern of the microbenthic community in the Pearl River Estuary.

Key words: Pearl River Estuary; macrobenthos; community structure

珠江全长2,320 $\mathrm{km}$, 流域面积 $453,690 \mathrm{~km}^{2}$, 是 我国年径流量仅次于长江的第二大河流。珠江口直 通南海, 是珠江的入海口, 也是广东最大的出海口, 与长江口、黄河口并称为中国的三大河口(王丽荣和 赵焕庭，2000)，其水域涵盖10种资源丰富和功能重 要的滨海湿地类型(王迪等, 2015); 同时也是港澳 地区重要的水产养殖区和渔场。因此生态环境质量 对珠江河口区经济建设和资源的可持续发展有着 重大影响(何桂芳等, 2002; 王晓明等, 2003), 开展 珠江口生态环境质量的监测与健康评价工作具有 十分重要的意义。

大型底栖动物是指不能通过孔径为 $0.5 \mathrm{~mm}$ 网 篎、生活史的全部或大部分时间生活于海洋沉积物 以及海水中物体(包括生物体和非生物体)底内、底 表的生物类群(袁兴中和陆健健, 2002; 蔡立哲, 2015), 是海洋生态系统中的重要组成成分。大型底 栖动物由于活动能力较弱且受环境变化影响显著, 研究其种类组成、群落结构、时空变化以及物种多 样性等特征, 一定程度上可以反映环境状况及其变 化(马骏和付荣恕, 2010), 也可以在污染监测和环境 质量评价中发挥作用(Taft \& Haig, 2005)。在珠江口 及邻近海域开展大型底栖动物研究已有部分报道, 但主要是利用底栖动物的部分类群如昆虫纲(王旭 涛等, 2016)、寡毛纲(蒋万祥等, 2011)等进行水质评 价; 在珠江口潮下带开展的大型底栖动物研究可以 追溯到20世纪80年代末(杞桑等, 1982; 杞桑和林美 心，1985; 苏炳之等，1989; 杞桑和黄伟建，1993), 这些研究表明历史上珠江口流域大型底栖动物以 水栖塞毛类、多毛类和软体类共同占优势, 节肢动 物也有大量种类出现。但2006-2007年在珠江口潮 下带的研究发现大型底栖动物各季度均以环节动 物种类最多(张敬怀, 2014), 王迪等2007年秋季在珠 江口潮间带湿地进行大型底栖动物群落研究则发
现甲壳类最多, 其次为多毛类和软体动物(王迪等, 2015), 与同期潮下带的底栖种类分布略有差别, 表 明随着时间的推移, 珠江流域环境变化对大型底栖 动物群落多样性造成显著影响。

鉴于珠江口潮间带大型底栖动物研究目前报 道有限, 且历史数据表明群落结构已随环境变迁而 变化, 因此有必要对该区域大型底栖动物的群落结 构以及主要影响因素再次进行研究, 并对河口湿地 环境质量进行生物学评价。通过2014年11月至2015 年8月在珠江河口区开展的大型底栖动物定量调查, 本文对大型底栖动物群落结构进行分析, 结合环境 因子数据, 以期反映珠江口生态环境的健康程度, 同时也为珠江口湿地的生态管理提供理论依据。

\section{采样及数据处理}

\section{1 站位布设和样品采集}

分别于2014年11月(秋季)、2015年2月(冬季)、 2015年5月(春季)和2015年8月(夏季), 在珠江口进 行 4 个季度大型底栖动物潮间带调查。本次调查布 设P01、P02和P03共3条断面(图1), 每条断面按高、 中、低潮区设 3 个取样站, 每个站位取 3 个平行样。 4 个季度共采得定量样品108份, 定性样品36份。所有 生物的采集、处理、实验室生物挑选和称重方法及 程序均按《海洋调查规范 第6部分: 海洋生物调查》 (GB/T 12763.6-2007)的要求进行。采样时, 用 $25 \mathrm{~cm}$ $\times 25 \mathrm{~cm} \times 30 \mathrm{~cm}$ 的样框和铲子采集泥样, 然后用 0.5 $\mathrm{mm}$ 孔径的篮网清洗, 将截留在篮网的生物和部分 残留物用体积分数为 $95 \%$ 的酒精固定后带回实验室, 进一步清洗、过篮、分选、鉴定和称重。

2014年11月另外采集沉积物样品进行有机碳、 总氮和底质粒径的测定; 同时, 每个季度利用YSI 环境监测系统(600QS-M-O, 美国)现场同步测量海 水的 $\mathrm{pH}$ 值、盐度、水温等环境因子。其中温度、盐 

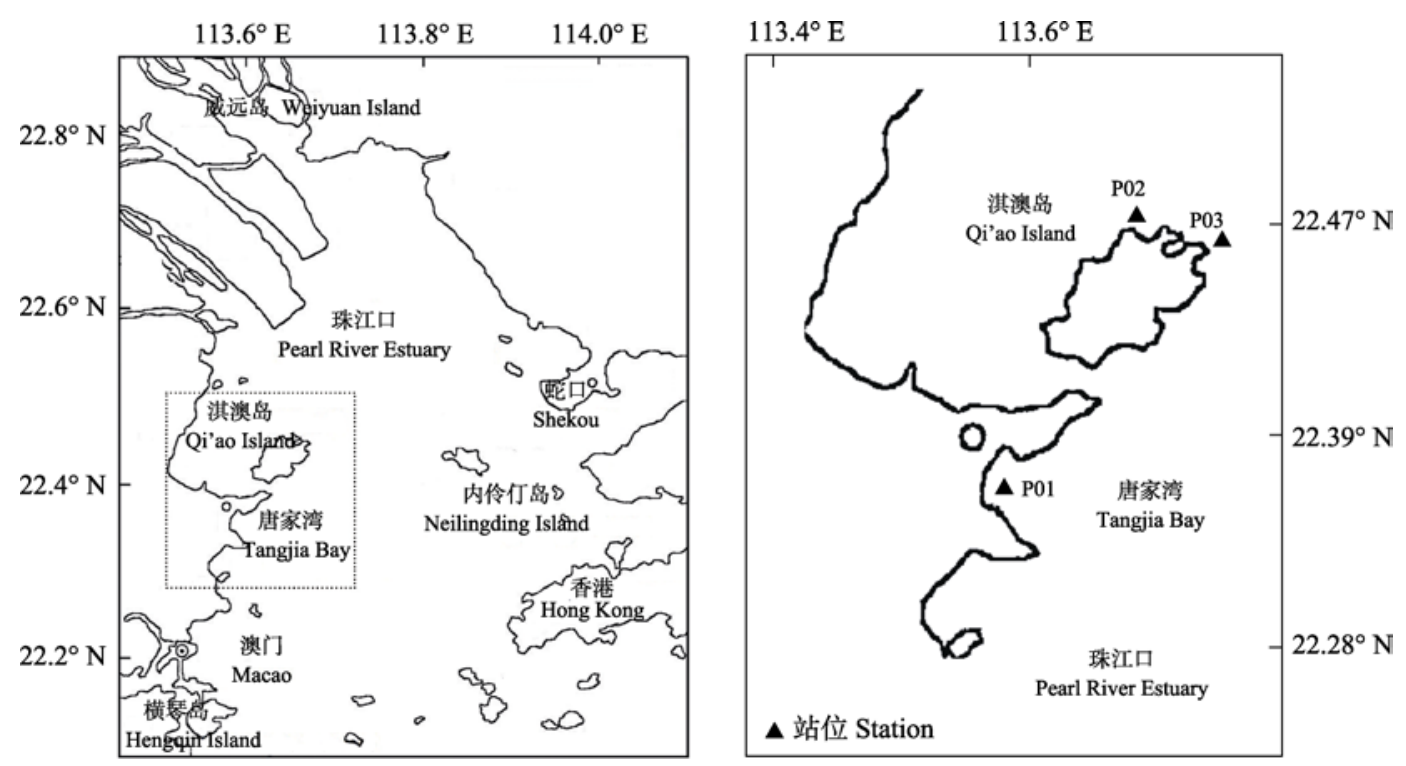

图1＼cjkstart珠江口大型底栖动物站位图(左图仿黄洪辉等, 2002)

Fig. 1 The sampling station of macrobenthos in the Pearl River Estuary. The left figure is an imitation from Huang et al, 2002.

度和 $\mathrm{pH}$ 值均为 4 个季度的平均值, 底质粒径、总氮 和总有机碳为2014年秋季采集的沉积物测得。根据 《海洋调查规范 第8部分: 海洋地质地球物理调查 一沉积物粒度分析》(GB/T 12763.8-2007), 粒径小 于 $4.00 \mu \mathrm{m}$ 的属于粘土, 4.00-63.00 $\mu \mathrm{m}$ 的属于粉砂, 大于 $63.00 \mu \mathrm{m}$ 的属于极细砂。

\section{2 数据处理}

计算大型底栖动物群落的Shannon-Wiener多样 性指数 $\left(H^{\prime}\right)$ 、均匀度指数 $\left(J^{\prime}\right)$ 和丰富度指数 $(D)$, 公式 如下:

$$
\begin{aligned}
& H^{\prime}=-\sum_{i=1}^{S} P_{i} \log _{2} P_{i} \\
& J^{\prime}=H^{\prime} / \log _{2} N \\
& D=S-1 / \log _{2} N
\end{aligned}
$$

式中, $S$ 为采集样品中大型底栖动物的种类数, $N$ 为样 品中所有种类的总个体数, $P_{i}$ 为样品中第 $\mathrm{i}$ 种的丰度 比例 $\left(n_{i} / N\right)$ 。参考我国《近岸海域环境监测规范》 (HJ442-2008), 以多样性指数计算结果进行环境质 量评价。

采用底栖生物优势度指数来判断优势种(徐兆 礼和陈亚㫿, 1989), 计算公式: $Y=\left(n_{i} / N\right) \times f_{i}$ 。式中, $n_{i}$ 为第 $\mathrm{i}$ 种的个体数; $N$ 为所有站位采集的底栖生物 总个体数; $f i$ 为该物种在各调查站位中出现的频率。 $Y \geq 0.02$ 时, 即认为该物种为优势种。

使用SPSS 22.0软件进行大型底栖动物的物种
数、密度、生物量、群落多样性指数与环境因子的 Pearson相关性分析。对大型底栖动物丰度进行平方 根转化, 以平衡优势种和稀有种对群落结构的影响, 并计算站位间的Bray-Curtis相似性系数, 构建相似 性矩阵, 然后采用Cluster等级聚类和非度量多维标 度排序(non-metric multi-dimensional scaling, nMDS) 分析珠江河口区大型底栖动物的群落分布格局。

\section{2 结果}

\section{1 珠江口环境因子测定结果}

珠江河口区底质中极细砂和粉砂含量较多, 而 粘土含量很少(表1)。P 01 断面的 $\mathrm{pH}$ 值高于 $\mathrm{P} 02$ 和 $\mathrm{P} 03$ 断面, P01高潮区的总氮和总有机碳最高, 温度和盐 度的最低值都出现在P03断面。

\section{2 珠江口大型底栖动物物种组成}

珠江口 4 个季度共获得大型底栖动物 52 种。其 中软体动物种类最多，有19种，占 $37 \%$; 多毛动物 有 16 种，占 $29 \%$; 甲壳动物有 12 种，占 $23 \%$; 其他动 物有5种，占 $11 \%$ 。 P 01、P02和P03断面获得的大型 底栖动物物种数分别为 36 种、 21 种和 15 种, 高潮区、 中潮区和低潮区获得的大型底栖动物物种数依次 为 $26 、 25$ 和 32 种。

珠江口 4 个季度大型底栖动物优势种组成有所 不同, 但均以软体动物为主(表2)。其中, 光滑河篮 蛤(Potamocorbula laevis)和中国绿螂(Glaucomya 
表1 珠江河口区各断面环境因素

Table 1 The environmental factors in different transections of Pearl River Estuary

\begin{tabular}{|c|c|c|c|c|c|c|c|c|c|}
\hline & \multicolumn{3}{|c|}{ P01 } & \multicolumn{3}{|c|}{ P02 } & \multicolumn{3}{|c|}{ P03 } \\
\hline & $\begin{array}{l}\text { 高潮区 } \\
\text { High tide }\end{array}$ & $\begin{array}{l}\text { 中潮区 } \\
\text { Middle tide }\end{array}$ & $\begin{array}{l}\text { 低潮区 } \\
\text { Low tide }\end{array}$ & $\begin{array}{l}\text { 高潮区 } \\
\text { High tide }\end{array}$ & $\begin{array}{l}\text { 中潮区 } \\
\text { Middle tide }\end{array}$ & $\begin{array}{l}\text { 低潮区 } \\
\text { Low tide }\end{array}$ & $\begin{array}{l}\text { 高潮区 } \\
\text { High tide }\end{array}$ & $\begin{array}{l}\text { 中潮区 } \\
\text { Middle tide }\end{array}$ & $\begin{array}{l}\text { 低潮区 } \\
\text { Low tide }\end{array}$ \\
\hline 粘土 Clay (\%) & 2.15 & 2.79 & 4.01 & 1.27 & 4.85 & 8.61 & 1.26 & 4.25 & 0.28 \\
\hline 粉砂 Silt (\%) & 18.06 & 21.65 & 28.47 & 15.51 & 50.95 & 76.36 & 18.73 & 48.59 & 3.13 \\
\hline 极细砂 Sand (\%) & 79.79 & 75.56 & 67.52 & 83.22 & 44.20 & 15.03 & 80.01 & 47.16 & 96.59 \\
\hline 总氮 TN (\%) & 0.23 & 0.04 & - & 0.02 & 0.03 & - & 0.05 & 0.05 & - \\
\hline 总有机碳 TOC (\%) & 1.83 & 0.37 & - & 0.22 & 0.21 & - & 0.60 & 0.70 & - \\
\hline 温度 Temperature $\left({ }^{\circ} \mathrm{C}\right)$ & 24.23 & & & 24.50 & & & 23.87 & & \\
\hline 盐度～Salinity (\%o) & 10.13 & & & 10.43 & & & 9.47 & & \\
\hline pH值 & 8.07 & & & 7.71 & & & 7.78 & & \\
\hline
\end{tabular}

- 该数据未检测 No data was detected

\section{表2 珠江河口区4个季度优势种及其优势度值 $(Y)$}

Table 2 The dominant species and their dominant values $(Y)$ of four seasons in Pearl River Estuary

\begin{tabular}{lllll}
\hline 种类 Species & 春季 Spring & 夏季 Summer & 秋季 Autumn & 冬季 Winter \\
\hline 环节动物 Annelida & & & & 0.022 \\
$\quad$ 羽须鳃沙蚕 Dendroneris pinnaticirrus & - & - & - & 0.603 \\
软体动物 Mollusca & & & 0.326 & 0.031 \\
$\quad$ 光滑河篮蛤 Potamocorbula laevis & 0.512 & 0.143 & 0.020 & 0.020 \\
$\quad$ 中国绿螂 Glaucomya chinensis & 0.067 & 0.128 & - & - \\
$\quad$ 焦河篮蛤 Potamocorbula ustulata & - & - & & \\
\hline
\end{tabular}

一该季度非优势种 The species was not dominant in this season
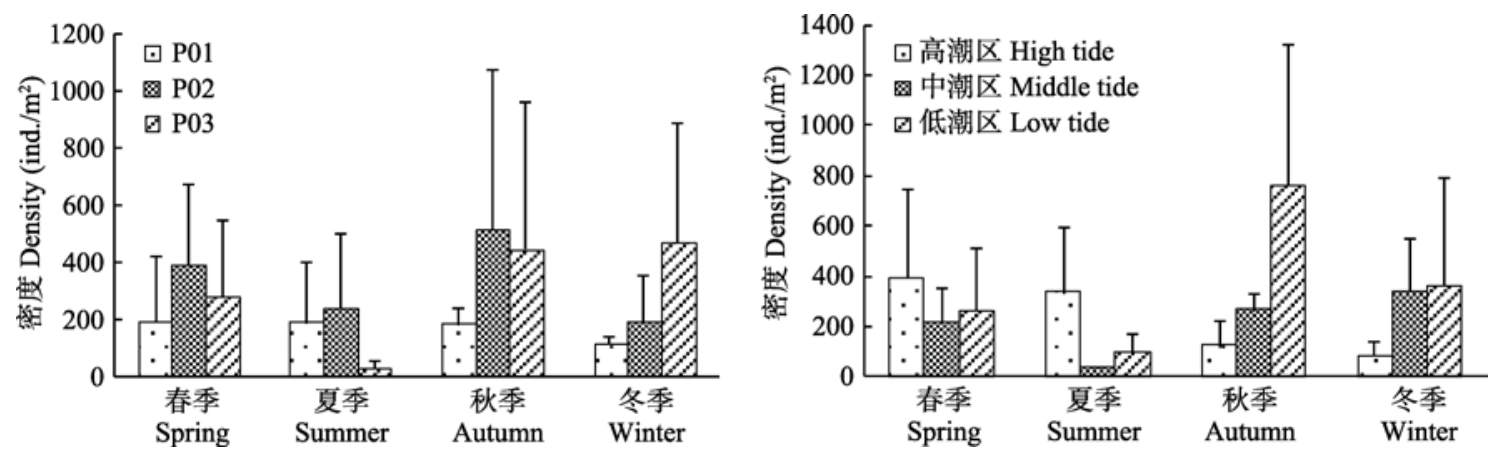

图2 珠江河口区大型底栖动物密度(平均值 + 标准差)的时空变化

Fig. 2 Spatial and temporal variation of macrobenthic density (mean + standard deviation) in Pearl River Estuary

chinensis)在 4 个季度均有大量出现。此外, 焦河篮蛤

(Potamocorbula ustulata)和羽须鳃沙蚕(Dendroneris pinnaticirrus)在冬季也作为优势种出现。

\section{3 珠江口大型底栖动物密度和生物量}

珠江河口区大型底栖动物年平均密度为 269.3 ind. $/ \mathrm{m}^{2}$, 时空变化如图2所示。P01断面平均密度最 低, 为 169.8 ind. $/ \mathrm{m}^{2}$; P03断面平均密度居中, 为 304.9 ind. $/ \mathrm{m}^{2}$; P02 断面平均密度最高, 为 334.2 ind. $/ \mathrm{m}^{2}$ 。从季节分布来看, 密度由高到低分别为秋
季 $>$ 冬季 $>$ 春季 $>$ 夏季, 其中平均密度最高出 现在P02断面秋季, 为515.6 ind. $/ \mathrm{m}^{2}$, 远高于秋季年 平均密度; 最低出现在 P03 断面夏季, 为 24.9 ind. $/ \mathrm{m}^{2}$, 远低于夏季平均密度。在垂直分布方面, 中 潮区平均密度最低, 为211.1 ind. $/ \mathrm{m}^{2}$, 高潮区居中, 为229.3 ind. $/ \mathrm{m}^{2}$, 低潮区最高, 为367.6 ind. $/ \mathrm{m}^{2}$ 。在不 同潮区中平均密度随着季节变化不尽相同，其中高 潮区平均密度最大值出现于春季, 而后呈下降趋势, 在冬季有最低值。中潮区和低潮区则是春、夏两季 
生物密度下降，秋、冬两季生物密度上升。

在密度组成方面, 软体动物的贡献最大, 年平 均密度达 245.8 ind. $/ \mathrm{m}^{2}$, 占总密度的 $91 \%$, 其中仅 P03断面秋季和冬季的光滑河篮蛤的密度就分别高 达334.22 ind. $/ \mathrm{m}^{2}$ 和 433.8 ind. $/ \mathrm{m}^{2}$ 。

珠江口大型底栖动物的年平均生物量为 129.61 $\mathrm{g} / \mathrm{m}^{2}$, 时空分布如图3所示。P01断面年平均生物量 最低, 为73.06 g/ $\mathrm{m}^{2}, \mathrm{P} 02$ 断面年平均生物量居中, 为 $113.32 \mathrm{~g} / \mathrm{m}^{2}, P 03$ 断面年平均生物量最高, 为 $202.43 \mathrm{~g} / \mathrm{m}^{2}$ 。其中 P01断面生物量变化幅度较小, 秋 季达最大值 $89.47 \mathrm{~g} / \mathrm{m}^{2}$, 冬季有最小值为 $45.69 \mathrm{~g} / \mathrm{m}^{2}$ 。 而P02和P03断面的生物量随季节变化较大, P02断 面生物量由春季到夏季逐渐下降, 秋季上升而冬季 又呈下降趋势，而P03断面的生物量则是春夏呈下 降趋势, 秋冬回升。生物量的垂直分布规律表现为

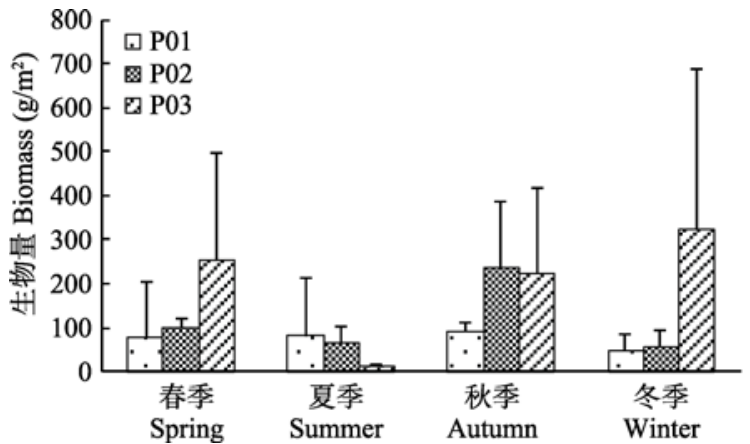

低潮区 $\left(192.73 \mathrm{~g} / \mathrm{m}^{2}\right)>$ 中潮区 $\left(111.06 \mathrm{~g} / \mathrm{m}^{2}\right)>$ 高潮 区 $\left(85.07 \mathrm{~g} / \mathrm{m}^{2}\right)$ 。低潮区平均生物量最高，做出最大 贡献的是秋季，远高于年平均生物量。

在生物量组成方面, 软体动物的贡献也最大, 年平均生物量达 $128.40 \mathrm{~g} / \mathrm{m}^{2}$ ，占总生物量的 $99 \%$, 其中仅P03断面秋季和冬季光滑河篮蛤的生物量就 分别高达 $126.71 \mathrm{~g} / \mathrm{m}^{2}$ 和 $270.21 \mathrm{~g} / \mathrm{m}^{2}$ 。

\section{4 珠江口大型底栖动物群落多样性}

珠江口 12 个站次的丰富度指数 $(D)$ 平均为 1.81 \pm 1.38 , 最高出现在P01秋季(3.92), 最低出现在P03 春季 $(0.20)$; 均匀度指数 $\left(J^{\prime}\right)$ 平均为 $0.50 \pm 0.27$, 最高 出现在P01冬季(0.81), 最低出现在P03春季(0.06); Shannon-Wiener多样性指数 $\left(H^{\prime}\right)$ 平均为 $1.60 \pm 1.13$, 最高出现在 P01秋季(3.39), 最低出现在 P03春季 (0.06) (表3)。珠江口区域大型底栖动物生物多样性

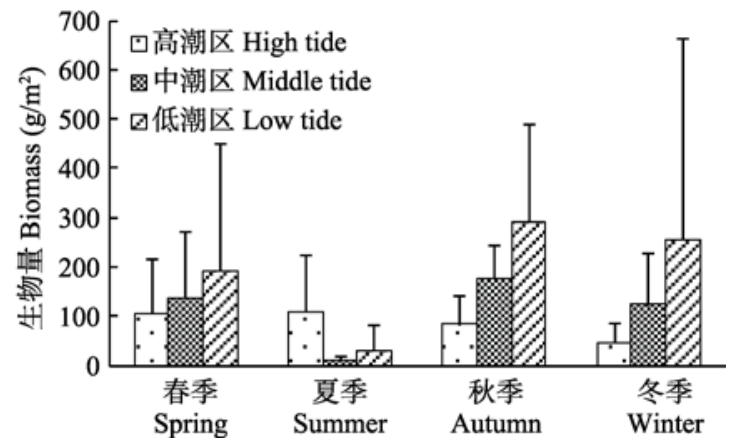

图3 大型底栖动物生物量(平均值 + 标准差)的时空变化

Fig. 3 Spatial and temporal variation of the biomass (mean + standard deviation) of macrobenthos

表3 珠江河口区4 个季度大型底栖动物群落的物种多样性指数

Table 3 Biodiversity indices of macrobenthic communities in four seasons in Pearl River Estuary

\begin{tabular}{|c|c|c|c|c|c|c|}
\hline $\begin{array}{l}\text { 站次 } \\
\text { Samplings }\end{array}$ & $\begin{array}{l}\text { 物种数 } \\
\text { Species } \\
\text { number }\end{array}$ & $\begin{array}{l}\text { 密度 } \\
\text { Density } \\
(\text { ind./m²) }\end{array}$ & $\begin{array}{l}\text { 生物量 } \\
\text { Biomass } \\
\left(\mathrm{g} / \mathrm{m}^{2}\right)\end{array}$ & $\begin{array}{l}\text { 丰富度指数 } \\
\text { Richness } \\
\text { index }(D)\end{array}$ & $\begin{array}{l}\text { 均匀度指数 } \\
\text { Evenness } \\
\text { index }\left(J^{\prime}\right)\end{array}$ & $\begin{array}{l}\text { Shannon-Wiener多样性指数 } \\
\text { Shannon-Wiener diversity } \\
\text { index }\left(H^{\prime}\right)\end{array}$ \\
\hline \multicolumn{7}{|l|}{ P01 } \\
\hline 秋季 Autumn & 19 & 183.1 & 89.47 & 3.92 & 0.80 & 3.39 \\
\hline 冬季 Winter & 14 & 113.8 & 45.69 & 3.18 & 0.81 & 3.09 \\
\hline 春季 Spring & 17 & 193.8 & 78.05 & 3.41 & 0.64 & 2.60 \\
\hline 夏季 Summer & 10 & 188.4 & 79.04 & 1.95 & 0.62 & 2.06 \\
\hline \multicolumn{7}{|l|}{ P02 } \\
\hline 秋季 Autumn & 19 & 515.6 & 236.83 & 3.17 & 0.31 & 1.30 \\
\hline 冬季 Winter & 4 & 190.2 & 53.15 & 0.64 & 0.21 & 0.42 \\
\hline 春季 Spring & 4 & 391.1 & 100.12 & 0.56 & 0.54 & 1.08 \\
\hline 夏季 Summer & 4 & 236.4 & 63.18 & 0.61 & 0.51 & 1.02 \\
\hline \multicolumn{7}{|l|}{ P03 } \\
\hline 秋季 Autumn & 7 & 446.2 & 222.87 & 0.92 & 0.40 & 1.03 \\
\hline 冬季 Winter & 4 & 469.3 & 323.93 & 0.54 & 0.22 & 0.45 \\
\hline 春季 Spring & 2 & 279.1 & 254.66 & 0.20 & 0.06 & 0.06 \\
\hline 夏季 Summer & 8 & 24.9 & 8.27 & 2.65 & 0.90 & 2.69 \\
\hline 平均值 \pm 标准差 Mean \pm SD & $9.3 \pm 6.3$ & $269.3 \pm 153.1$ & $129.61 \pm 101.49$ & $1.81 \pm 1.38$ & $0.50 \pm 0.27$ & $1.60 \pm 1.13$ \\
\hline
\end{tabular}


水平波动较大, 指示环境质量在极差 $\left(H^{\prime}<1.0\right)$ 和优 良 $\left(H^{\prime} \geq 3.0\right)$ 之间。其中P01断面秋季和冬季的环境 质量为优良, P01断面春季和夏季、P03断面夏季的 环境质量为一般, 而P02断面冬季、P03断面夏季和 秋季的环境质量极差, 且物种均匀度和丰富度水平 极低, 可见该区域环境不适合大多数底栖生物生存。

将各个站位的物种数、密度、生物量和生物多 样性指数与环境因子进行Pearson相关性分析。结果 表明, 物种数、丰富度指数 $(D)$ 与盐度相关性显著, 物种数与 $\mathrm{pH}$ 值相关性极显著; 其他因子之间相关 性均不显著(表4)。

\section{5 珠江口大型底栖动物群落结构相似性分析}

Cluster等级聚类分析结果显示(图4), 在相似性 为 $45.57 \%$ 时, 可将珠江河口区大型底栖动物分为 3
组，第一组包括 P01断面的 4 个季度; 第二组包括 P02断面和P03断面的春季、秋季和冬季; 且P02断 面的春季和夏季群落相似性更高; 第三组为P03断 面夏季。nMDS分析结果表明, Stress $=0.09$ ，表明图 中站位间的相互关系是可以信任的(图5)。nMDS结 果与聚类分析结果一致, P01断面聚集为一组且与 P02断面和P03断面相隔较远，P02断面4个季度和 P03断面 4 个季度存在交叉聚集，表明P02断面与P03 断面群落更为相似，而两者与 $\mathrm{P} 01$ 断面相似度较低。

\section{3 讨论}

\section{1 珠江口大型底栖动物群落特征分析}

大型底栖动物中很多种类在发育完成时，由于 活动能力不强, 只能生活在固定场所或者有限的范

表4 生物多样性指数与环境因子的Pearson相关分析

Table 4 Pearson correlation between species biodiversity indices and environmental factors

\begin{tabular}{lllllll}
\hline & $\begin{array}{l}\text { 物种数 } \\
\text { Species } \\
\text { number }\end{array}$ & $\begin{array}{l}\text { 密度 } \\
\text { Density }\end{array}$ & $\begin{array}{l}\text { 生物量 } \\
\text { Biomass }\end{array}$ & $\begin{array}{l}\text { 丰富度指数 } \\
\text { Richness index } \\
(D)\end{array}$ & $\begin{array}{l}\text { 均匀度指数 } \\
\text { Evenness index } \\
\left(J^{\prime}\right)\end{array}$ & $\begin{array}{l}\text { Shannon-Wiener多样性指数 } \\
\text { Shannon-Wiener index }\left(H^{\prime}\right)\end{array}$ \\
\hline 总有机碳 Total organic carbon (\%) & 0.703 & 0.233 & 0.486 & 0.716 & 0.447 & 0.682 \\
总氮 Total nitrogen (\%) & 0.757 & 0.285 & 0.440 & 0.803 & 0.352 & 0.720 \\
粘土 Clay (\%) & -0.247 & 0.215 & 0.496 & -0.053 & -0.459 & -0.104 \\
粉砂 Silt (\%) & -0.502 & 0.207 & 0.494 & -0.317 & -0.482 & -0.369 \\
极细砂 Sand (\%) & 0.483 & -0.208 & -0.496 & 0.296 & 0.482 & 0.347 \\
温度 Temperature $\left({ }^{\circ} \mathrm{C}\right)$ & 0.080 & 0.504 & -0.053 & 0.119 & 0.305 & 0.185 \\
盐度 Salinity (\%) & $0.623^{*}$ & 0.483 & -0.051 & $0.577 *$ & 0.163 & 0.366 \\
$\mathrm{pH}$ & $0.958^{* *}$ & -0.179 & 0.015 & 0.272 & 0.023 & 0.144 \\
\hline
\end{tabular}

${ }^{*} P \leq 0.05 ; * * P \leq 0.01$

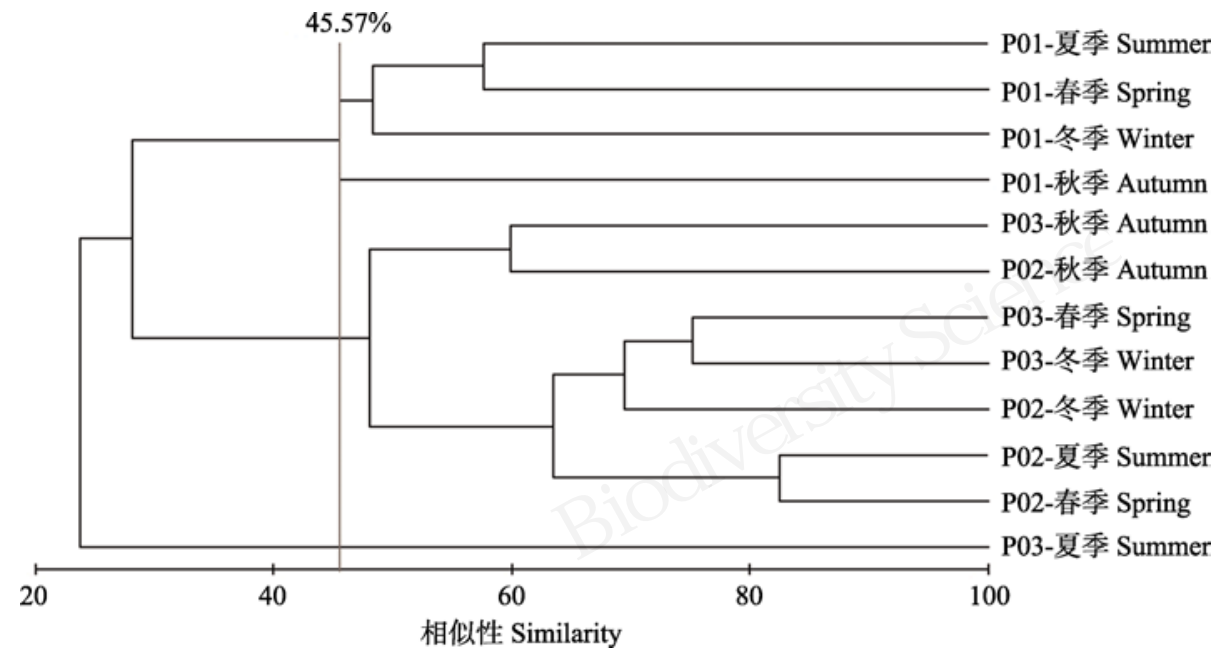

图4 珠江河口区4 个季度大型底栖动物的聚类分析

Fig. 4 Cluster analysis of macrobenthic community in four seasons in Pearl River Estuary 


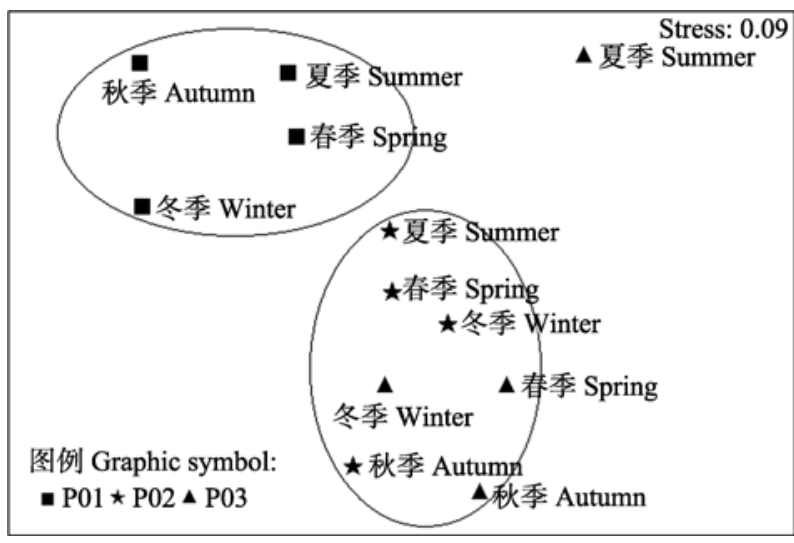

图5 珠江河口区4个季度大型底栖动物nMDS标序分析 Fig. 5 nMDS analysis of macrobenthic community in four seasons in Pearl River Estuary

围内(李乃成等, 2015), 因此常被用于反映一个生境 中长期的环境变化。本研究中, P01断面的物种数和 多样性指数明显高于P02和P03断面, 而生物量和密 度却明显低于P02和P03断面, 我们推测这与 3 条断 面环境因子的差异有关。P02和P03断面皆位于淇澳 岛, 环境因子更为接近, 沉积物中粉砂比例明显高 于P01断面, 但 $\mathrm{pH}$ 值却小于P01断面(表1)。而P01断 面总碳和总氮平均值高于 P02和P03断面, 表明 P01 断面有更多来自陆源的有机污染物但仍未达到污 染水平。由此可见, 中等程度的干扰更有利于维持较 高的物种多样性, 但不利于维持较高的物种密度。

在潮区分布方面, 低潮区物种数、密度和生物 量最高, 而中潮区和高潮区则相对较低, 与大型底 栖动物研究的一般规律一致。不同潮区被海水淹没 的时间不一样, 而大型底栖动物对海水的耐受性不 同, 所以不同潮区大型底栖动物分布不同。中潮区 和高潮区需要面临更长时间的裸露与暴晒, 对于大 多数大型底栖动物都是不利的环境, 因此物种数、 密度和生物量都较低。

在季节变化方面, 大型底栖动物物种数、密度、 生物量和多样性指数随季节有明显变化, 其中最能 解释群落多样性分布特征的环境因子为盐度和 $\mathrm{pH}$ 值。盐度差异大是河口区显著的宏观特征, 潮汐日 变化和降水量的季节变化对河口区的海水盐度造 成显著影响。此外, 河口区是海陆作用最为剧烈、 生态结构最为复杂的区域, 同时当前人为因素影响 呈现超过自然因素的趋势(赖廷和等, 2019), 这些不 可控又难以量化的因素叠加并进一步影响了大型 底栖动物群落的变化。

\section{2 大型底栖动物群落结构分析}

珠江河口区大型底栖动物Cluster聚类分析和 nMDS分析结果一致: P01断面与P02、P03断面群落 相似度较低; P02断面和P03断面4个季度群落相似 度较高。从采样的地理位置来看, P01断面靠近珠江 口西侧, 而P02断面与P03断面位于珠江口的淇澳岛 东北侧, 空间距离上P02、P03断面与P01断面距离较 远。其次, P03断面夏季与其他断面的群落相似度最 低, 与 $\mathrm{P} 03$ 断面夏季软体动物的密度和生物量急剧 下降有关。再者, P01断面有互花米草(Spartina alterniflora)入侵，而P02、P03断面附近有牡蚛养殖 活动, 物种入侵和渔业养殖活动对大型底栖动物群 落结构也将造成影响。影响海洋生物多样性的因素 多而复杂，从大范围的全球气候变化至区域性的人 类活动，如沿海区域富营养化、物种入侵、渔业 (Smith et al, 2000)等。

\section{3 珠江口大型底栖动物群落的时间变化}

历史上在珠江口进行的大型底栖动物研究主 要在潮下带开展(彭松耀等, 2010, 2019; 毛婕昕等, 2011; 张敬怀, 2014), 在潮间带仅有少数报道(黄少 峰等, 2011; 王迪等, 2015)。本研究2014-2015年4个 季度获得的珠江口潮间带大型底栖动物以软体动 物、多毛动物和甲壳动物为主体，与王迪等(2015) 获得的物种组成结果一致。在物种多样性方面, 本 研究获得的大型底栖动物物种数(52种)高于黄洪辉 等(2002)(32种)、王迪等(2015)(43种)和黄少峰等 (2011)(40种)的调查结果, 而低于其他潮下带的调 查结果(表5)。王迪等在珠江口潮间带湿地获得的物 种数最接近本研究, 黄洪辉等和黄少峰等分别在潮 下带和潮间带进行了两个季度的珠江口大型底栖 动物调查, 取样频次的减少降低了物种数的获得, 但总体上同样在潮间带开展调查的研究获得的物 种数更接近, 可见潮间带和潮下带的大型底栖动物 多样性有明显差异。

根据本文的研究结果, 盐度和 $\mathrm{pH}$ 值是最能解 释群落多样性分布特征的环境因子。河口区大型底 栖动物的物种分布随着盐度梯度而变化(Ysebaert et al, 2003), 且处于 30\%o-34\%o盐度范围内的底栖生物 群落物种丰富度较高, 若处在5\%-8\%o盐度范围内, 群落的物种丰富度较低(Gaston et al, 1998)。河口区 潮间带和潮下带的盐度差异显著, 本文涉及研究区 域不大，盐度在 $9.5 \%$ - $10.5 \%$ 之间，与表5中其他在 
表5 珠江河口区大型底栖动物物种数、密度和生物量的历史与现状比较

Table 5 Historical and current status of the species number, density and biomass of macrobenthos in Pearl River Estuary

\begin{tabular}{|c|c|c|c|c|c|c|}
\hline $\begin{array}{l}\text { 调查年份 } \\
\text { Investigation year }\end{array}$ & $\begin{array}{l}\text { 物种数 } \\
\text { Species number }\end{array}$ & $\begin{array}{l}\text { 春季密度 } \\
\text { Density in spring } \\
\text { (ind. } / \mathrm{m}^{2} \text { ) }\end{array}$ & $\begin{array}{l}\text { 夏季密度 } \\
\text { Density in summer } \\
\text { (ind./ } \mathrm{m}^{2} \text { ) }\end{array}$ & $\begin{array}{l}\text { 春季生物量 } \\
\text { Biomass in spring } \\
\left(\mathrm{g} / \mathrm{m}^{2}\right)\end{array}$ & $\begin{array}{l}\text { 夏季生物量 } \\
\text { Biomass in summer } \\
\left(\mathrm{g} / \mathrm{m}^{2}\right)\end{array}$ & $\begin{array}{l}\text { 参考文献 } \\
\text { Reference }\end{array}$ \\
\hline 1999-2000 & 32 & 591.7 & - & 26.70 & - & Huang et al, 2002 \\
\hline 2004 & 223 & $2,011.0$ & 859.3 & 439.69 & 189.06 & Mao et al, 2011 \\
\hline 2005 & 240 & 183.0 & 138.5 & 127.17 & 25.36 & Mao et al, 2011 \\
\hline 2006 & 209 & 94.0 & 28.5 & 31.14 & 13.53 & Mao et al, 2011 \\
\hline 2008 & 293 & 251.7 & 215.0 & 27.15 & 38.91 & Mao et al, 2011 \\
\hline 2006 & 245 & - & 205.3 & - & 14.31 & Zhang, 2014 \\
\hline 2009 & 40 & $* *$ & $* *$ & $* *$ & $* *$ & Huang et al, 2011 \\
\hline 2015 & 67 & 215.0 & 212.0 & 11.79 & 3.32 & Peng et al, 2019 \\
\hline 2015 & 52 & 288.0 & 149.9 & 144.28 & 50.16 & 本研究 This study \\
\hline
\end{tabular}

-未采集该季度数据; **所参考文献中未显示该数据

- No data was collected in the season; ** No specific data was shown from the reference.

潮下带开展的研究相比处于较低的水平, 因而物种 数更低。

历年数据显示珠江河口区春、夏两季底栖动物 种群密度和生物量均随着时间的变化而逐渐减小, 并且趋势非常明显。季节变换带来的水温差异通过 影响大型底栖动物的产卵和繁殖, 进一步影响其密 度。本文中光滑河篮蛤和中国绿螂在春季的优势度 值远高于夏季。这类喜好近岸泥沙混合底质、个体 生物量大、喜群居的双壳类, 在珠江口潮下带调查 当中也大量出现在春、秋两季(黄洪辉等, 2002; 彭 松耀等, 2019)。此外, 杨洁等(2007)在厦门海域也发 现光滑河篮蛤密度在春季最高, 并认为其密度和生 物量与有机质、硫化物含量之间均无显著相关关系, 但降雨量增加引起的海水盐度降低更有利于光滑 河篮蛤的生长。光滑河篮蛤能忍受一定盐度变化, 它可以分布在淡水和海水之间, 繁殖和发育更合适 的盐度是5\%-25\%o之间(Soemodinoto et al, 1995), 珠江口的盐度范围适宜光滑河篮蛤的繁殖与生长, 使其在近些年的调查中始终处于优势地位。

珠江河口区在近20年内生态环境经历了一定 的变化, 这些因素造成了本次调查与之前调查之间 获取大型底栖动物种类、数量和生物量的不同。这 也说明了潮间带特别是河口湿地大型底栖生物调 查中影响因素的偶然性和复杂性, 生态系统的脆弱 性叠加人类活动的干扰, 经过几年的变迁, 珠江口 大型底栖动物群落已经发生了较大变化。

\section{参考文献}

Cai LZ (2015) Zoobenthic Ecology in Shenzhen Bay. Xiamen University Press, Xiamen. (in Chinese) [蔡立哲 (2015) 深 圳湾底栖动物生态学. 厦门大学出版社, 厦门.]

Gaston GR, Rakocinski CF, Brown SS, Cleveland CM (1998) Trophic function in estuaries: Response of macrobenthos to natural and contaminant gradients. Marine \& Freshwater Research, 49, 833-846.

He GF, Yuan GM, Li FQ (2002) Effect of economic development on water quality in Zhujiang Estuary. Marine Environmental Science, 23(4), 50-52. (in Chinese with English abstract) [何桂芳, 袁国明, 李凤岐 (2002) 珠江口沿岸城 市经济发展对珠江口水质的影响. 海洋环境科学, 23(4), 50-52.]

Huang HH, Lin YT, Li CH, Lin Q, Cai WG, Gao DY, Jia XP (2002) Ecology study on the benthic animals of Pearl River Estuary. Acta Ecologica Sinica, 22, 603-607. (in Chinese with English abstract) [黄洪辉, 林燕棠, 李纯厚, 林钦, 蔡 文贵, 高东阳, 贾晓平 (2002) 珠江口底栖动物生态学研 究. 生态学报, 22, 603-607.]

Huang SF, Liu Y, Li C, Huang JM (2011) Influence of reclamation on macrobenthic community in the Pearl River Estuary. Chinese Journal of Applied and Environmental Biology, 17, 499-503. (in Chinese with English abstract) [黄少 峰, 刘玉, 李策, 黄晋沐 (2011) 珠江口滩涂围剭对大型 底栖动物群落的影响. 应用与环境生物学报, 17 , 499-503.]

Jiang WX, Lai ZN, Peng SY, Gao Y, Yang WL, Pang SX (2011) Primary study of macroinvertebrate community structure in the Pearl River Guangzhou portion. Environmental Monitoring in China, 27(5), 69-72. (in Chinese with English 
abstract) [蒋万祥, 赖子尼, 彭松耀, 高原, 杨婉玲, 庞世 勋 (2011) 珠江广州段底栖动物群落结构初步研究. 中 国环境监测, 27(5), 69-72.]

Lai TH, He BY, Huang ZJ, Tang Q, Qin LY, Zhu T, Mo ZN, Liu L, Zhong YX (2019) Study on the macrozoobenthic community structure in intertidal zone of Fangchenghe Estuary of Guangxi, China. Journal of Tropical Oceanography, 38(2), 70-80. (in Chinese with English abstract) [赖廷和, 何斌源, 黄中坚, 汤乔, 覃漉雁, 朱婷, 莫珍妮, 刘俐, 钟 云旭 (2019) 防城河口湾潮间带大型底栖动物群落结构 研究. 热带海洋学报, 38(2), 70-80.]

Li NC, Liu XS, Xu ZD, Zhao R, Shi HH (2015) Biodiversity of macrofauna in the southern waters of Miaodao Archipelago. Biodiversity Science, 23, 41-49. (in Chinese with English abstract) [李乃成, 刘晓收, 徐兆东, 赵瑞, 石洪华 (2015) 庙岛群岛南部海域大型底栖动物多样性. 生物多样性, 23, 41-49.]

Ma J, Fu RS (2010) Progress of ecology research on macrobenthos. Shandong Agricultural Sciences, (2), 78-81. (in Chinese with English abstract) [马骏, 付荣恕 (2010) 大型底栖动物生态学研究进展. 山东农业科学, (2), 78-81.]

Mao JX, Yan QL, Wang LJ (2011) Changes trend of species number, biomass and density of zoobenthos in typical estuaries of China. Marine Environmental Science, 30, 37-40. (in Chinese with English abstract) [毛婕昕, 间启仑, 王立 俊 (2011) 典型河口底栖动物种类数、生物量及种群密度 变化趋势的研究. 海洋环境科学, 30, 37-40.]

Peng SY, Lai ZN, Mai YZ (2019) Distribution of quantity and diversity of macrobenthos in the Pearl River Estuary. Marine Fisheries, 41, 266-277. (in Chinese with English abstract) [彭松耀, 赖子尼, 麦永湛 (2019) 珠江口大型底 栖动物数量与生物多样性的分布特征. 海洋渔业, 41 , 266-277.]

Peng SY, Lai ZN, Jiang WX, Gao Y, Pang SX, Yang WL (2010) Study on community structure of macrozoobenthos and impact factors in Pearl River estuary. Acta Hydrobiologica Sinica, 34, 1179-1189. (in Chinese with English abstract) [彭松耀, 赖子尼, 蒋万祥, 高原, 庞世勋, 杨婉 玲 (2010) 珠江口大型底栖动物的群落结构及影响因子 研究. 水生生物学报, 34, 1179-1189.]

Qi S, Lin MX, Li KH (1982) Water pollution assessment of Pearl River, Guangzhou, by using benthic macroinvertebrates. Acta Scientiae Circumstantiae, 2, 181-189. (in Chinese with English abstract) [杞桑, 林美心, 黎康汉 (1982) 用大型底栖动物对珠江广州河段进行污染评价. 环境科学学报, 2, 181-189.]

Qi S, Lin MX (1985) Further assessment of pollution status of Pearl River, Guangzhou, by using benthic macroinvertebrates. Acta Scientiae Circumstantiae, 5, 354-359. (in Chinese with English abstract) [杞桑, 林美心 (1985) 用大
型底栖动物再次对珠江广州河段污染的评价. 环境科学 学报, 5, 354-359.]

Qi S, Huang WJ (1993) The benthic macroinvertebrate community relating to the water quality in lower Zhujiang (Pearl River). Acta Scientiae Circumstantiae, 13, 80-86. (in Chinese with English abstract) [杞桑, 黄伟建 (1993) 珠江 三角洲底栖动物群落与水质关系. 环境科学学报， 13 , 80-86.]

Smith CR, Austen MC, Boucher G, Heip C, Hutchings PA, King GM, Koike I, Lambshead PJD, Snelgrove P (2000) Global change and biodiversity of marine sediments: Impacts and linkages across the sediment-water interface. BioScience, 50, 1108-1120.

Soemodinoto A, Oey BL, Ibkar-Kramadibrata H (1995) Effect of salinity decline on macrozoobenthos community of Cibeureum River Estuary, Java, Indonesia. Oceanographic Literature Review, 42, 1116-1120.

Su BZ, Li WX, Lai ZX (1989) Investigation of benthic fauna in the Pearl River system (Guangdong river section). Chinese Journal of Zoology, 24(3), 15-19. (in Chinese) [苏炳之, 黎 伟新, 赖泽兴 (1989) 珠江水系(广东江段)底栖动物调查. 动物学杂志, 24(3), 15-19.]

Taft OW, Haig SM (2005) The value of agricultural wetlands as invertebrate resources for wintering shorebirds. Agriculture, Ecosystems and Environment, 110, 249-256.

Wang D, Lin ZJ, Peng YC, Li TJ, Ma Y (2015) Macrobenthos community status of the Pearl River Delta coastal wetland in autumn 2007. Marine Science, 39, 70-78. (in Chinese with English abstract) [王迪, 林昭进, 彭艳超, 李团结, 马玉 (2015) 2007年秋季珠江三角洲典型滨海湿地大型底栖动 物群落现状. 海洋科学, 39, 70-78.]

Wang LR, Zhao HT (2000) Common features of the estuarine wetland in China. Marine Science Bulletin, 19(5), 47-54. (in Chinese with English abstract) [王丽荣, 赵焕庭 (2000) 中 国河口湿地的一般特点. 海洋通报, 19(5), 47-54.]

Wang XM, Zhong MJ, Liao WB, Lan CY (2003) The sustainable development strategy on resources and environment in Zhujiang Estuary and adjacent islands. Acta Scientiarum Naturalium University Sunyatsen, 42(6), 73-77. (in Chinese with English abstract) [王晓明, 仲铭锦, 廖文波, 蓝崇钰 (2003) 珠江口沿岸地区资源环境及其可持续发展措施. 中山大学学报(自然科学版), 42(6), 73-77.]

Wang XT, Xie Z, Liu W, Xu S (2016) Bioassessment of water quality using benthic macroinvertebrates in major rivers of Pearl River Basin. Water Resources Protection, 32(3), 94-98, 136. (in Chinese with English abstract) [王旭涛, 谢 昭, 刘威, 徐盛 (2016) 珠江重要河流底栖动物水质生物 学评价. 水资源保护, 32(3), 94-98, 136.]

Xu ZL, Chen YQ (1989) Aggregated intensity of dominant species of zooplankton in autumn in the East China Sea and Yellow Sea. Chinese Journal of Ecology, 8(4), 13-15. (in 
Chinese with English abstract) [徐兆礼, 陈亚篧 (1989) 东 黄海秋季浮游动物优势种聚集强度与鲐鯺渔场的关系. 生态学杂志, 8(4), 13-15.]

Yang J, Cai LZ, Liang JY, Zhou XP, Jin L, Chen ZH (2007) Quantitative analysis of two new dominant species of macrozoobenthos in Xiamen Harbour, China. Marine Sciences, 31(9), 44-49. (in Chinese with English abstract) [杨洁, 蔡立哲, 梁俊彦, 周细平, 金亮, 陈志鸿 (2007) 厦门海域大型底栖动物两个优势种的发现及其数量分析. 海洋科学, 31(9), 44-49.]

Ysebaert T, Herman PMJ, Meire P, Craeymeersch J, Verbeek H, Heip CHR (2003) Large-scale spatial patterns in estuaries: Estuarine macrobenthic communities in the Schelde Estuary, NW Europe. Estuarine, Coastal and Shelf Science, 57, 335-355.
Yuan XZ, Lu JJ (2002) Ecological characteristics of macrozoobenthic community of tidal flat wetland in the Changjiang Estuary. Resources and Environment in the Yangtze Basin, 11, 414-420. (in Chinese with English abstract) [袁兴中, 陆健健 (2002) 长江口潮滩湿地大型底栖动物群落的生 态学特征. 长江流域资源与环境, 11, 414-420.]

Zhang JH (2014) The variation of biodiversity of macrobenthic fauna with salinity and water depth near the Pearl Estuary of the northern South China Sea. Biodiversity Science, 22, 302-310. (in Chinese with English abstract) [张敬怀 (2014) 珠江口及邻近海域大型底栖动物多样性随盐度、水深的 变化趋势. 生物多样性, 22, 302-310.]

(责任编委: 李新正 责任编辑: 间文杰) 